\title{
Prediction equations for single breath diffusing capacity (TICO) in a middle aged caucasian population
}

\author{
B R Thompson, ${ }^{1,2}$ D P Johns, ${ }^{3}$ M Bailey, ${ }^{4}$ J Raven, ${ }^{1,4}$ E H Walters, ${ }^{3,4}$ M J Abramson ${ }^{1,4}$
}

- Additional data are available in an online repository, published online only at http://thorax.bmj. com/content/vol63/issue10

${ }^{1}$ Allergy, Immunology and Respiratory Medicine, The Alfred Hospital, Melbourne, Victoria, Australia; ${ }^{2}$ Department of Physiology, Monash University, Victoria, Australia; ${ }^{3}$ Respiratory Research Group, Menzies Research Institute, University of Tasmania, Tasmania, Australia; ${ }^{4}$ Department of Epidemiology and Preventive Medicine, Monash University, Victoria, Australia

Correspondence to:

Dr B Thompson, Lung Function Laboratory, Allergy Immunology and Respiratory Medicine, The Alfred Hospital, Commercial Rd, Melbourne 3004, Victoria, Australia; b.thompson@ alfred.org.au

Received 9 October 2007 Accepted 16 March 2008 Published Online First 4 April 2008

\section{ABSTRACT}

Background: There are many reference equations for the measurement of single breath carbon monoxide diffusing capacity of the lung (TIco). However, the testing methodologies vary and there are no well documented studies that have developed reference equations for TIco and alveolar volume (VA) in middle aged and older populations.

Aims: (1) Develop reference equations for TIco in a middle aged population using the current American Thoracic Society/European Respiratory Society (ATS/ERS) guidelines; (2) compare the equations with those commonly used in laboratories around the world. Methods: Healthy subjects (498 male and 474 female) aged 45-71 years were recruited as part of a larger epidemiological study. All participants completed a respiratory questionnaire and had spirometry and single breath TIco (corrected for haemoglobin) measurements following ATS/ERS guidelines.

Results: Mean age was 58 years for males and 57 years for females. For males, factors that predicted TIco were: height, age, age $\times$ height interaction and being an exsmoker. For females, factors that predicted Tlco were: height, age, weight and an age $\times$ height interaction.

Conclusion: We have described new prediction equations for Tlco in a middle aged population that require validation in other populations.

There are many studies describing prediction equations for the measurement of single breath carbon monoxide diffusing capacity of the lung (TlCo). ${ }^{1-6}$ These studies have demonstrated that the main predictors of Tlco are height, gender and age. Significant limitations of the previous studies include small sample sizes, ${ }^{37}$ non-standardised equipment $\mathrm{t}^{135}$ and different concentrations of inspired oxygen. ${ }^{13-7}$ Importantly, previous prediction equations have been based on populations that included only relatively few subjects older than 55 years. However, in clinical practice, Tlco is most likely to be measured in this age group as many respiratory diseases such as chronic obstructive pulmonary disease (COPD) are predominantly confined to older patients.

Despite evidence of increasing morbidity in older people with respiratory disease, knowledge of normal respiratory function in this population is limited. Diffusing capacity along with spirometry is the cornerstone of the clinical guidelines for the diagnoses of COPD and other pulmonary conditions. ${ }^{89}$ Current measurements are compared with "normal" values which have been calculated using algorithms derived from population studies of healthy volunteers. Only relatively recently have publications reported normal values for spirometry in those aged over 70 years in European ${ }^{10}$ and American ${ }^{11}$ populations, which show departures of $20 \%$ or more obtained in predictive values compared with those obtained from extrapolations of equations derived in younger people. Neither of these studies included Tlco measurements.

The existing studies on Tlco normative values have a number of methodological differences. All existing studies have used manual or semi-automated Tlco measurement equipment. ${ }^{1-7}$ However, currently used testing systems are fully computerised and, depending on the manufacturer, differ in the methodology of the gas analysers, flow measuring devices, analogue to digital converters and sample rates. All of these factors can affect the measured Tlco. ${ }^{12-15}$

Finally, the population sampled has a significant effect on the outcomes of the study. In a recent study, ${ }^{1}$ weight was shown to be a significant predictor of Tlco and Tlco/alveolar volume (VA) (Kco) in the female population. However, in this Spanish study, the distribution of weight was limited, again making the equations susceptible to extrapolation errors in broader clinical populations.

To address the above methodological issues, we set out to develop a set of prediction equations for Tlco and VA in a large "normal" middle aged and older population using modern computerised equipment, specifically following guidelines produced by the American Thoracic Society/European Respiratory Society (ATS/ERS). ${ }^{9}$

\section{METHODS}

\section{Subject selection}

Tlco and VA were obtained in caucasian subjects with no history of lung disease based on questionnaires, who either never smoked or were former smokers. Lung function was not used to define normality as it can become a circular argument when creating new prediction equations for "normal" subjects. The subjects were recruited as part of another larger epidemiological study of COPD. ${ }^{16}$ All patients had TlCo and spirometry measured, and were administered the European Community Respiratory Health Study (ECRHS) questionnaire $^{17-19}$ (see online repository for further details). Smoking status was based on standard Australian smoking questions. ${ }^{20}$ Anyone with serum cotinine $>100 \mu \mathrm{mol} / \mathrm{l}$ was reclassified as a current smoker and excluded from the analysis. We further excluded any subject who met Global Obstructive Lung Disease (GOLD) ${ }^{21}$ criteria for COPD stage 2 or greater. The study was approved by the ethics committee at The Alfred, Melbourne, Australia. All participants gave written informed consent. 
Table 1 Anthropometric and respiratory measurements of the study sample

\begin{tabular}{|c|c|c|}
\hline & $\begin{array}{l}\text { Males } \\
\text { (median (5-95\% centile)) }\end{array}$ & $\begin{array}{l}\text { Females } \\
\text { (median (5-95\% centile)) }\end{array}$ \\
\hline $\mathrm{n}$ & 498 & 474 \\
\hline $\mathrm{FEV}_{1}$ (I) & $3.75(2.57-4.84)$ & $2.71(1.96-3.61)$ \\
\hline FVC (I) & $4.92(3.61-6.33)$ & $3.48(2.60-4.57)$ \\
\hline FER $(\%)$ & $77.0(65-85)$ & $78.0(68-85.3)$ \\
\hline Height (m) & $1.75(1.64-1.87)$ & $1.62(1.52-1.71)$ \\
\hline Weight (kg) & $83.0(66-109)$ & $69.0(53.8-92.3)$ \\
\hline BMI $\left(\mathrm{kg} / \mathrm{m}^{2}\right)$ & $27(22.5-34.6)$ & $26(20.9-36)$ \\
\hline Age (y) & $57.0(47-70)$ & $57.0(47-70)$ \\
\hline Haemoglobin & $15.2(13.7-16.9)$ & $13.7(12.1-15.5)$ \\
\hline TIco (mmol/min/kPa) & $9.17(6.80-12.0)$ & $6.63(4.97-8.61)$ \\
\hline VA (I) & $6.71(5.06-8.29)$ & $4.88(3.82-6.09)$ \\
\hline
\end{tabular}

$\mathrm{BMI}$, body mass index; $F E R$, forced expired ratio; $\mathrm{FEV}_{1}$, forced expired volume in $1 \mathrm{~s}$; $\mathrm{FVC}$, forced vital capacity; TIco, carbon monoxide transfer factor; $\mathrm{V}_{\mathrm{A}}$, alveolar volume.

\section{Measurement of TIco and alveolar volume}

Single breath Tlco was measured in duplicate on a fully computerised system (Medgraphics Profiler, Minnesota, USA, software V.4a) according to ATS/ERS guidelines. ${ }^{9}$ This testing system uses gas chromatography for the measurement of gas concentrations and a pitot tube for measurement of flow. The inspired gas mixture contained $0.3 \%$ carbon monoxide, $0.5 \%$ neon, $20.6 \%$ oxygen, with the balance, nitrogen. Breathhold time was calculated as described by Jones-Meade, ${ }^{22}$ washout and sample volumes were set to 0.91 and an interval between repeat tests was at least $4 \mathrm{~min}$. At least two measurements were performed which had to agree to within $1 \mathrm{mmol} / \mathrm{min} / \mathrm{kPa}$ or $10 \%$, whichever was greater, otherwise further measurements were made until repeatable results were obtained. All Tlco results were corrected to a standard haemoglobin concentration of $14.6 \mathrm{~g} / \mathrm{dl}$ using the method described by Cotes. ${ }^{13}$ Standing height $(\mathrm{m})$ and body weight $(\mathrm{kg})$ were measured without shoes.

\section{Quality control of equipment}

The quality control of the flow and volume signals was performed using a pulmonary waveform generator initially, an explosion decompression device monthly and biological control weekly. The flow sensor was also calibrated prior to each testing session using a 31 certified syringe. The accuracy of the Tlco and VA measurements was determined monthly using a custom built validator. The Tlco and VA validator consisted of a 31 certified syringe and two accurately known concentrations of inspired and expired $\mathrm{CO}$ and $\mathrm{Ne}$ to simulate typical inspired and expired gas concentrations. With the two gas mixtures it was possible to simulate a measured Tlco and VA value with known limits of agreement $(7.20-7.43 \mathrm{mmol} / \mathrm{min} / \mathrm{kPa}$ for Tlco and 3.15-3.25 1 for VA). Tlco measurements were taken at ATPS and subject dead space correction was not included. ${ }^{23}$ Further detail of the methods is supplied in the online repository, including the results of the quality assurance programme for the testing equipment.

\section{Statistical analysis}

All analyses were performed using SAS V.8.2 (SAS Institute, Cary, North Carolina, USA) or SPSS V.15.0 (SPSS, Chicago, Illinois, USA). Multivariate linear regression models were constructed using a stepwise selection technique and validated using a backwards elimination technique. Each model was then assessed for clinical and biological plausibility. A two sided $\mathrm{p}$ value of 0.05 was considered statistically significant.

\section{RESULTS}

We recruited 1201 subjects into the study; 147 were excluded as current smokers, 41 had doctor diagnosed COPD and one was excluded for dwarfism. We then excluded a further four subjects with incomplete smoking data and 36 with undiagnosed COPD (GOLD stage 2 or greater), leaving a total of 972 subjects (498 male and 474 female).

Table 1 shows the demographic details of the sample. All subjects were aged between 45 and 71 years with a relatively even distribution across the ages up to 70 years. Of the 498 males, 248 (50\%) were ex-smokers, and of the 491 females, 159 (34\%) were ex-smokers. The mean pack year history of the exsmokers was 13 (range 5-28).

\section{Prediction equations for Tlco and $V_{A}$ in males}

Both linear and more complex higher order models and interactions between variables were explored. The model that gave the best fit was one in which height was cubed, age squared and included an interaction between age and being an ex-smoker (table 2). This model explained over one-third of the variance in TlCo. Predicted VA was a simpler linear equation which included the terms height and weight which described nearly half of the variance in VA.

Table 2 Prediction equations for TIco and $V_{A}$ in males and females

\begin{tabular}{|c|c|c|c|}
\hline & Prediction equation & $\mathbf{R}^{2}(\%)$ & SD \\
\hline \multicolumn{4}{|l|}{ Males } \\
\hline TIco & $1.109^{*} \mathrm{Ht}^{3}-0.000402^{*} \mathrm{~A}^{2}-0.035^{*} \mathrm{~A}{ }^{*} \mathrm{ExSm}+1.805^{*} \mathrm{ExSm}+4.696$ & 36.0 & 3.71 \\
\hline Tlco $0^{95 \text { th }}$ & $1.10{ }^{*} \mathrm{Ht}^{3}-0.000402^{*} \mathrm{~A}^{2}-0.035^{*} \mathrm{~A}^{*} \mathrm{ExSm}+1.805^{*} \mathrm{ExSm}+6.741$ & & \\
\hline Tlco $0^{5 \text { th }}$ & $1.109^{*} \mathrm{Ht}^{3}-0.000402^{*} \mathrm{~A}^{2}-0.035^{*} \mathrm{~A}^{*} \mathrm{ExSm}+1.805^{*} \mathrm{ExSm}+2.651$ & & \\
\hline$V_{A}$ & $10.155^{*} \mathrm{Ht}-0.013^{*} \mathrm{Wt}-0.0000943^{*} \mathrm{~A}^{2}-9.628$ & 47.8 & 0.69 \\
\hline$V_{A}{ }^{95 \text { th }}$ & $10.155^{*} \mathrm{Ht}-0.013^{*} \mathrm{Wt}-0.0000943^{*} \mathrm{~A}^{2}-8.501$ & & \\
\hline$V_{A^{5 t h}}$ & $10.155^{*} \mathrm{Ht}-0.013^{*} \mathrm{Wt}-0.0000943^{*} \mathrm{~A}^{2}-10.755$ & & \\
\hline \multicolumn{4}{|l|}{ Females } \\
\hline TIco & $51.900^{*} \mathrm{Ht}-3.901 * \mathrm{Ht}^{3}+0.375^{*} \mathrm{Age}+0.012^{*} \mathrm{Wt}-0.273^{*} \mathrm{~A}^{*} \mathrm{Ht}-57.703$ & 36.2 & 2.73 \\
\hline TIc0 $0^{95 t h}$ & $51.900^{*} \mathrm{Ht}-3.901 * \mathrm{Ht}^{3}+0.375^{*} \mathrm{Age}+0.012^{*} \mathrm{Wt}-0.273^{*} \mathrm{~A}^{*} \mathrm{Ht}-56.200$ & & \\
\hline Tlco $0^{\text {th }}$ & $51.900^{*} \mathrm{Ht}-3.901 * \mathrm{Ht}^{3}+0.375^{*} \mathrm{Age}+0.012^{*} \mathrm{Wt}-0.273^{*} \mathrm{~A}^{*} \mathrm{Ht}-59.207$ & & \\
\hline$V_{A}$ & $7.206^{*} \mathrm{Ht}-0.0041^{*} \mathrm{Wt}-0.0073^{*} \mathrm{Age}{ }^{*} \mathrm{Ht}-5.77$ & 35.6 & 0.56 \\
\hline$V_{A}^{95 \text { th }}$ & $7.206^{*} \mathrm{Ht}-0.0041^{*} \mathrm{Wt}-0.0073^{*} \mathrm{Age}{ }^{*} \mathrm{Ht}-4.856$ & & \\
\hline$V_{A}{ }^{\text {th }}$ & $7.206^{*} \mathrm{Ht}-0.0041^{*} \mathrm{Wt}-0.0073^{*} \mathrm{Age}{ }^{*} \mathrm{Ht}-6.684$ & & \\
\hline
\end{tabular}

A, age (y); ExSm, ex-smoker (ex-smoker is a binary term in which ex-smoker is 1 and never smoker is 0 ); Ht, height $(\mathrm{m})$; TIco, carbon monoxide diffusing capacity of the lung; $V_{A}$, alveolar volume. 


\section{Prediction equations for TIco and $V_{A}$ in females}

The model that gave the best fit for Tlco in the female population was one that included height, height cubed, age, weight and an age-height interaction (table 2). Similar to the equations for males, this model explained $36 \%$ of the variance. The equation for $\mathrm{VA}$ was also similar to the male equation including height and weight but it also included an age-height interaction term and explained one-third of the variance.

\section{Age-height interaction}

In our sample, there was an interaction between age and height that was a significant predictor for all outcomes in females. The effect of an age-height interaction was a greater rate of decline in age related Tlco with increasing height. That is, the taller the subject the more rapid the decline in Tlco with age (see fig 1 in the online repository). This interaction is a novel finding which significantly increases the total explanatory power of the model.

\section{Comparison with other equations}

Table 3 gives the mean predicted Tlco for other published prediction equations using our data set. In our sample, Tlco expressed as per cent predicted was systematically lower using all of the previous commonly used prediction equations. This is highly likely to reflect the older population included in our study. The previous prediction equations that best fitted our
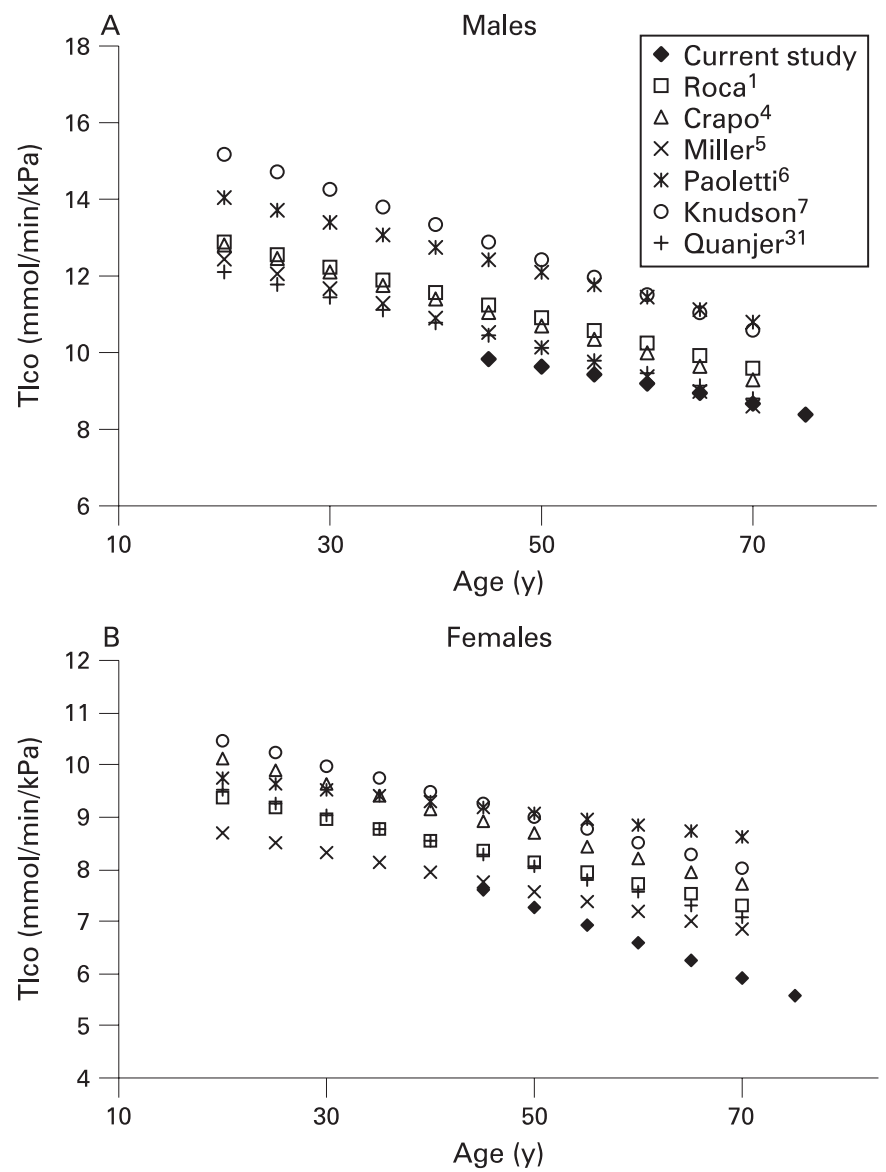

Figure 1 ( $A, B)$ Carbon monoxide diffusing capacity of the lung (TIco) vs age for males (A) and females (B). Height for males was assumed to be the mean height in our sample $(1.75 \mathrm{~m}$ for males and $1.62 \mathrm{~m}$ for females). Weight in the females was assumed to be the mean measured weight of the sample $(70.4 \mathrm{~kg})$. The Miller equations were those of the non-smoking group.
Table 3 Comparison of mean per cent predicted Tlco in this sample using other published equations

\begin{tabular}{lcclll}
\hline & \multicolumn{2}{l}{ Mean TIco $\%$ predicted } & & $\mathbf{R}^{2}$ & \\
\cline { 2 - 3 } \cline { 5 - 6 } & Males & Females & & Males & Females \\
\hline Present study & 100 & 100 & & 0.36 & 0.36 \\
Roca $^{1}$ & 90 & 85 & & 0.44 & 0.37 \\
Crapo $^{4}$ & 82.5 & 80.3 & & 0.6 & 0.6 \\
Miller $^{5}$ & 96.3 & 91.3 & & 0.46 & 0.54 \\
Paoletti $^{6}$ & 79.4 & 74.8 & & \\
Knudson $^{7}$ & 78.6 & 77.1 & & \\
\hline
\end{tabular}

Tlco, carbon monoxide diffusing capacity of the lung.

sample were those of Miller and colleagues. ${ }^{5}$ Conversely, the equations of Knudson and colleagues ${ }^{7}$ substantially overestimated the observed mean Tlco in both males and females.

\section{DISCUSSION}

We have developed a new set of prediction equations for the measurement of Tlco and VA for a middle aged and older population using current computerised equipment and methods. We have shown that there are major differences in our equations compared with previous studies that were mainly developed in younger populations (table 3 ). The importance is that a significant proportion of patients seen in a clinical lung function laboratory are in this particular age group, making our new equations more clinically relevant.

Many of the respiratory disorders that use Tlco to help diagnosis, such as parenchymal and pulmonary vascular lung diseases, occur predominantly in an older population. Previous equations ${ }^{13-57}$ have had relatively few subjects (eg, eight males ${ }^{3}$ ) in older age groups (>60 years) compared with younger $(<40$ years) age groups. Inclusion of relatively few older subjects has led to the equations being susceptible to error in this group. Moreover, extrapolating the equations to patients with an age greater than those included in a specific study can lead to considerable error, especially if the data are biased to a younger population. Previous studies looking at spirometric prediction equations in an older population have shown differences of up to $20 \%$ compared with extrapolating equations generated from a younger population. ${ }^{10}{ }^{11}$ Mean age of the subjects in our study was substantially older than other recent studies of normal Tlco ranges, where the mean age has been as young as 35 years. ${ }^{1}$ Over half of the subjects in our sample were more than 55 years of age.

\section{Smoking status}

A substantial minority of the subjects included in our study were classified as ex-smokers, which improves the generalisability of our prediction equations. Although most of these subjects had only a limited smoking history, separate analyses to develop separate prediction equations for Tlco based on the never smokers and ex-smokers were performed. While the regression curves were slightly different (fig 2 in the online repository), especially in the older subjects, this was not statistically significant. Nonetheless, being an ex-smoker was a significant predictor of Tlco in our male population. There may have been some under-reporting of previous smoking in this population, or there may have been some other confounding factor, such as passive smoking/occupational exposures, to explain the results. Furthermore, there was an interaction between age and being an ex-smoker. Ex-smoker status was 
only a significant predictor for Tlco in males and not females, who may have smoked less.

\section{Comparison with other equations}

This is the first study to describe a set of prediction equations for the measurement of TlCo and VA in a middle aged and older population. Moreover, we have shown a number of interactions between predictors that had significant effects on the outcome. Previous studies have mainly confined predictors to height and age. $^{13-57}$ However, some other authors have used terms including weight. ${ }^{1}$ Previous studies have also tested for nonlinear effects and also performed various transformations, which have added little to the strength of the models. ${ }^{15} \mathrm{We}$ confirmed that the improvement in $\mathrm{R}^{2}$ using complex higher order terms was small compared with the use of simple linear equations. However, we believe it makes little difference to the end user as most equations are now incorporated within the software of the measuring device.

The subjects studied were sampled randomly for another larger epidemiological study. ${ }^{17}$ There is much controversy in the literature regarding the inclusion of ex-smokers. Some studies have found statistically different measurements of Tlco in smokers versus non-smokers, but we did not find this in our group. Ex-smokers would be expected to have a lower Tlco than never smokers. As a high proportion of patients presenting to a pulmonary function laboratory are former smokers, the ability to adjust for this factor improves the likelihood of detecting pulmonary disease.

One methodological difference between various prediction equation studies is the fractional inspired oxygen $\left(\mathrm{FiO}_{2}\right)$ of the inspired mixture. It is well known that the higher the $\mathrm{FiO}_{2}$ the lower the measured Tlco. ${ }^{24}$ The various published studies have used an $\mathrm{FiO}_{2}$ value ranging from $18 \%{ }^{1}$ to $25 \%{ }^{4}$ For the study that used $25 \%$, the reason for the higher $\mathrm{FiO}_{2}$ was to counteract the effect of that study being performed at an altitude of $1520 \mathrm{~m}$. However, the majority of the studies have used an $\mathrm{FiO}_{2}$ of approximately $21 \%$. Nevertheless, there are still large differences in measured TlCo across the various equations that use the same $\mathrm{FiO}_{2}$ (fig $1 \mathrm{~A}, \mathrm{~B}$ ). One exception is the equations published by Roca and colleagues ${ }^{1}$ : if these were corrected to an $\mathrm{FiO}_{2}$ of $21 \%$ this would reduce the overall Tlco, leading to similar results obtained in the current study and the equations published by Miller and colleagues. ${ }^{5}$

An important consideration when using prediction equations is the crossover age from one set of equations to another. Although rarely a problem in an adult population, this issue is highlighted when changing from equations based on children to equations from an adult population as an individual patient reaches adulthood. From fig $1 \mathrm{~A}$ and $\mathrm{B}$, the issue is highlighted at 45 years of age where the equations for the current study start. The equations that minimise the difference in Tlco at 45 years of age are those published by Miller and colleagues, ${ }^{5}$ Quanjer, ${ }^{25}$ Crapo and Morris ${ }^{4}$ and Roca and colleagues. ${ }^{1}$

\section{Weight term}

Weight was first demonstrated by Roca et a ${ }^{1}$ to be a significant predictor of Tlco in females. However, the weight term may falsely elevate the predicted Tlco, especially in overweight and obese subjects. Part of this is likely because of the narrow weight range that was included in the population studied (60$75 \mathrm{~kg}^{1}$ ). Therefore, previously published equations need to be extrapolated on a relatively frequent basis making the predicted value unreliable. This is especially the case with the documented increase in obesity in the population. ${ }^{26}$ Not including the weight term would lead to increased numbers of people with reduced Tlco relative to their predicted values solely based on their weight.

Further analysis of BMI demonstrated that $1.9 \%$ of the subjects were classified as underweight (BMI $<20 \mathrm{~kg} / \mathrm{m}^{2}$ ), $29.2 \%$ were of ideal weight (BMI 20-25), 47.3\% were classified as overweight (BMI 26-30) and $21.6 \%$ of subjects were classified as obese (BMI >30). There was a positive relationship between weight and Tlco. However, the maximum difference in mean Tlco between the groups was only $0.60 \mathrm{mmol} / \mathrm{min} / \mathrm{kPa}$. Furthermore, it was the overweight not the obese group that led to the significant weight term in the equation. The mean Tlco for the overweight group was $0.60 \mathrm{mmol} / \mathrm{min} / \mathrm{kPa}$ higher than the ideal weight $(p<0.001)$ whereas in the obese subjects the Tlco was only 0.35 higher than the ideal weight group.

\section{Effect of equipment and testing methodology on the measurement}

There are relatively few studies that have entirely complied with the ATS/ERS criteria ${ }^{9}$ for the measurement of Tlco. Importantly, existing studies have significant methodological differences in the measurement of Tlco relating to the calculation of breathhold time, $\mathrm{FiO}_{2}$ and deadspace correction. Moreover, there have not been any published prediction equations using fully computerised equipment. The type of analyser used for the $\mathrm{CO}$ analysis, type of insoluble inert marker gas used for the calculation of VA and estimating the initial alveolar CO concentration may all play a part in contributing to the variability of the measurement of Tlco. Our study is up to date, using modern equipment and methods.

Calculation of breathhold time has also been shown to be important, leading to differences of up to $6.8 \%$ in measured TlCO $^{27}$ between the method described by the Epidemiology Standardisation Project ${ }^{28}$ and Ogilvie and colleagues. ${ }^{29}$ Using the breathhold time calculation, as described by Jones and Meade, ${ }^{22}$ gives a similar measured Tlco to that of Ogilvie and colleagues. ${ }^{29}$ The ATS criteria stipulate the Jones-Meade calculation, which is what was used in the current study.

The Medgraphics system uses gas chromatography for the analysis of tracer gases. Also peculiar to this system is the use of neon as the insoluble inert tracer gas. Neon has a relatively low diffusivity and therefore likely to distribute further throughout the lung, leading to a higher measured alveolar volume than helium. ${ }^{30}$ Even though the latest ATS/ERS ${ }^{9}$ document states that the tracer should have a diffusivity closer to that of helium, there are now large numbers of computerised devices that use different gases such as methane and helium.

\section{CONCLUSION}

We have developed a set of prediction equations for an older population using modern computerised equipment. The equations generated gave a significantly higher predicted Tlco than most of those previously published. ${ }^{1367}$ Most of the differences are likely to be explained by the older population, but methodological differences cannot be excluded. The latest ATS/ERS guidelines for the performance of Tlco state that prediction equations need to be selected carefully taking into account important methodological differences. This is one of the few studies using fully computerised equipment, gas chromatography for the gas analysis and neon as the tracer gas. Furthermore, we have developed a set of prediction 
equations more specific to an older population which are therefore likely to be the most clinically relevant available.

Acknowledgements: Biljana Skoric and Melanie Matheson assisted with data collection and management.

Funding: National Health and Medical Research Council grant.

Competing interests: None.

Ethics approval: The study was approved by the ethics committee at The Alfred, Melbourne, Australia.

\section{REFERENCES}

1. Roca J, Rodriguez-Roisin R, Cobo E, et al. Single-breath carbon monoxide diffusing capacity prediction equations from a Mediterranean population. Am Rev Respir Dis 1990;141:1026-32.

2. Neder JA, Andreon S, Pere C, et al. Reference values for lung function tests. III. Carbon monoxide diffusing capacity (transfer factor). Braz J Med Biol Res 1999;32:729-37.

3. Roberts CM, MacRae KD, Winning AJ, et al. Reference values and prediction equations for normal lung function in a non-smoking white urban population. Thorax 1991;46:643-50

4. Crapo RO, Morris AH. Standardized single breath normal values for carbon monoxide diffusing capapcity. Am Rev Respir Dis 1981;123:185-9.

5. Miller A, Thorton JC, Warshw R, et al. Single breath diffusing capacity in a representative sample of the population of Michigan, a large industrial state. Am Rev Respir Dis 1983;127:279-87.

6. Paoletti P, Viegi G, Pistelli G, et al. Reference equations for the single breath diffusing capacity. A cross-sectional analysis and effect of body size and age. Am Rev Respir Dis 1985;132:806-13.

7. Knudson RJ, Kaltenborn WT, Knudson DE, et al. The single-breath carbon monoxide diffusing capacity. Reference equations derived from a healthy non-smoking population and effects of hematocrit. Am Rev Respir Dis 1987;135:805-11.

8. McKenzie DK, Frith PA, Burdon JGW, et al. The COPDX Plan: Australian and New Zealand Guidelines for the management of chronic obstructive pulmonary disease. Med J Aust 2003;178:S1-40.

9. Macintyre N, Crapo RO, Viegi G, et al. Standardisation of the single breath determination of carbon monoxide uptake in the lung. Eur Respir J 2005;26:720-35.

10. Garcia-Rio F, Pino JM, Dorgham A, et al. Spirometric reference equations for European females and males aged 65-85 yrs. Eur Respir J 2004;24:397-405.

11. Enright $\mathbf{P}$, Krinmal $R$, Higgins $M$, et al. Spirometric reference values for women and men 65 to 85 years of age. Am Rev Respir Dis 1993;147:125-33.

12. Yeh MP, Adams TD, Gardner RM, et al. Effect of $\mathrm{O}_{2}, \mathrm{~N}_{2}$, and $\mathrm{CO}_{2}$ composition on the non-linearity of Fleisch pneumotach characteristics. J Appl Physiol Respir Environ Exercise Physiol 1984;56:1423-5.
13. Cotes JE. Effect of variability in gas analysis on the reproducibility of the pulmonary diffusing capacity by the single breath method. Thorax 1963;18:151-4.

14. Cotes JE. Lung function. Assessment and application in medicine. Oxford: Blackwell Scientific Publications, 1993.

15. Chinn DJ, Naruse Y, Cotes JE. Accuracy of gas analysis in lung function laboratories. Thorax 1986;41:133-7.

16. Abramson M. Respiratory symptoms and lung function in older people with asthma or COPD. Med J Aust 2005; 183(Suppl 1):S23-5.

17. Matheson MC, Benke G, Raven J, et al. Biological dust exposure in the workplace is a risk factor for chronic obstructive pulmonary disease. Thorax 2005;60:645-51.

18. European Community Respiratory Health Study (ECRHS) questionnaire. http://www. ecrhs.org (accessed 22 July 2008)

19. Fletcher C, Peto R, Tinker C, et al. The natural history of chronic bronchitis and emphysema. Oxford: Oxford University Press, 1976.

20. Australian Institute of Health and Welfare. National Health Data Dictionary, v. 10 AIHW Catalogue No. HWI 30. Canberra: Australian Institute of Health and Welfare, 2001.

21. National Institutes of Health, National Heart, Lung and Blood Institute. Global strategy for the diagnosis, management, and prevention of chronic obstructive pulmonary disease. NHLBI/WHO Workshop Report. Bethesda: NHLBI/WHO, 2001; publication No 2701.

22. Jones RS, Meade FA. A theoretical and experimental analysis of anomalies in the estimation of pulmonary diffusing capacity by the single-breath method. $0 \mathrm{~J}$ Exp Physiol 1961; 46:131-43

23. Johns DP, Rochford PD, Imberger H. Questionnaire based study of inter-laboratory variability of the single breath TLCO test: instrumentation, technique, calculation, quality control and predicted values. Volume 1985;5:4-13.

24. Crapo R0, Kanner RE, Jensen RL, et al. Variability of the single-breath carbon monoxide transfer factor as a function of inspired oxygen pressure. Eur Respir $J$ 1988; 1:573-4.

25. Quanjer P. Standardized lung function testing. Bull Eur Physiopath Respir 1983;19:39-44.

26. Cameron AJ, Welborn TA, Zimmet PZ, et al. Overweight and obesity in Australia: the 1999-2000 Australian Diabetes, Obesity and Lifestyle Study (AusDiab). Med J Aust 2003;178:427-32.

27. Leech JA, Martz L, Liben A, et al. Diffusing capacity for carbon monoxide. The effects of different derivations of breathhold time and alveolar volume and of carbon monoxide back pressure on calculated results. Am Rev Respir Dis 1985;132:1127-9.

28. Ferris BG. Epidemiology standardisation project. Am Rev Respir Dis 1978;118(part 2):55-111.

29. Ogilvie CM, Forster RE, Blackmore WS, et al. A standardized breath-holding technique for the clinical measurement of the diffusing capacity for carbon monoxide. J Clin Invest 1957;36:1-17.

30. Crawford ABH, Makowska M, Paiva M, et al. Convection-dependent and diffusiondependent ventilation maldistribution in normal subjects. J Appl Physiol 1985;59:838-46.

\section{Drug and Therapeutics Bulletin (DTB)}

\section{Your key source of unbiased, independent advice}

For over 45 years DTB has been an independent, indispensable part of evidence-based clinical practice. DTB offers healthcare professionals detailed assessment of, and practical advice on, individual medicines and other treatments, groups of treatment and the overall management of disease.

DTB is now also available online at http://dtb.bmj.com:

- browse or search all DTB content from the latest issue back to 1994

- email alerting, sophisticated searching, RSS feeds and full text links from cited references

- interactive services such as My Folders for quick access to articles that you have viewed previously and My Searches to save and re-use useful searches

- comment online on any DTB article

To subscribe, or for further information, please visit http://dtb.bmj.com 